Motrivivência $\quad$ Ano XX, $\quad N^{\circ}$ 30, P. 61-75 Jun./2008

\title{
Homoafetividade nas Aulas de Educação Física: e agora?
}

\author{
Homoafetividade on lessons of \\ physical education: and now?
}

João Marcos Aquino'
Vera Lícia Baruk ${ }^{2}$
Norma Rejane Ribas ${ }^{3}$
Mirian Lange Noal ${ }^{4}$

\section{Resumo Abstract}

Este artigo tem como objetivo verificar a atuação do professor de Educação Física diante da questão da homoafetividade em suas aulas.

Para alcançar os objetivos, este estudo apropriou-se da pesquisa de campo de caráter qualitativo e contou com a participação de cinco sujeitos homoafetivos (18 a 26 anos), cinco sujeitos heteroafetivos

e cinco professores de Educação Física de ambos os sexos, que foram submetidos a uma entrevista semi-

This article aims to verify the performance of the teacher of Physical Education before the question of homoafetividade in their classes. To achieve the objectives, this study used as a tool for field research of qualitative nature and had as participants homoafetivos five subjects ( 18 to 26 years), five heteroafetivos subjects and five Physical Education teachers of both sexes, which were submitted to a semi-structured interview with

1 Graduado em Educação Física pela Universidade Católica Dom Bosco (UCDB). Contato: markskako@hotmail.com

2 Mestre em Educação. Especialista em Preparação Física. Docente do Curso de Educação Física da Universidade Católica Dom Bosco (UCDB). Contato: vlbaruki@terra.com.br

3 Mestre em Ciências do Movimento Humano (UFSM). Coordenadora do curso de Educação Física da Universidade Católica Dom Bosco (UCDB). Contato: norma@top.com.br

4 Doutorado em Educação (UNICAMP). Docente do Curso de Educação Física (Universidade Católica Dom Bosco - UCDB). Contato: mirianoal@terra.com.br 
estruturada com perguntas formuladas sob três pontos fundamentais: participação nas aulas de educação

física, atitudes preconceituosas e postura profissional. Feita a coleta de dados as entrevistas foram transcritas para posterior análise mediante o procedimento da Análise de Discurso. Deste estudo observamos que a atuação dos professores de Educação Física frente as questões da homoafetividade ainda não é presente nas aulas, a não ser quando surge uma situação de conflito entre os alunos, mas não é tratado como conteúdo ou presente neles.

Este assunto aparece nas aulas de Educação Física por situações provocadas pelo corpo discente.

Palavras chave: Homoafetividade. Professor de Educação Física. questions based on three fundamental points: participation in physical education classes, prejudiced attitudes and professional attitude. Once the data collection interviews were transcribed for later analysis by the procedure of analysis of discourse. In this study we observed that the performance of teachers of Physical Education with the issues of homoafetividade is not present in class unless there is a situation of conflict between students, but is not treated as content or present them. This issue appears in the classes of Physical Education in situations caused by the teachers.

Keywords: Homoafetividade. Professor of Physical Education.

de existirem estudos realizados sobre a homoafetividade, estes ainda representam um número pequeno em relação à relevância e complexidade que o tema exige em termos de discussão e amadurecimento pelas partes envolvidas nas escolas: professores, alunos e a sociedade.

A presença de alunos homoafetivos nas escolas, de certa forma, exige que o corpo docente e discente se integre do assunto e se atualize a fim de trabalhar e discutir com propriedade aspectos inerentes a ele em suas aulas quando for necessário. 
Algumas questões surgiram das observações em aulas onde estavam presentes alunos homoafetivos: houve algum tipo ação discriminatória?em que momento foram percebidos? Esta discriminação sempre existiu?

Estas indagações nos remetem a história da Educação Física quando nos apresenta vários momentos de preconceito, como na relação que ela estabeleceu durante muitos anos entre esporte e gênero, ou seja, estereótipos que foram impostos pela família e pela sociedade de que a visão do corpo perfeito é fator determinante para funções físicas, sociais e culturais que esta mesma sociedade escolhe e impõe. Oliveira (2002) ao abordar a história da Educação Física escolar no período compreendido entre 1968 e 1984 relata que a obrigatoriedade imposta pela lei 5692/71 ocorreu devido ao interesse na qualidade da eficiência produtiva no mercado considerando como meio a educação escolarizada. Além disso, o decreto 69450/71 impôs padrões de referência para as aulas o que resultou em um padrão considerado uma maneira cômoda de atender aos anseios do governo e inicia-se então o ensino dos esportes institucionalizados com seus fundamentos técnicos, repetição em detrimento a riqueza de movimentos da cultura corporal.
Mesmo assim, com todas estas características seletivas da época que caracterizava a Educação Física escolar, ela atualmente tem uma grande participação no tocante ao gênero, pois é nela que trabalhamos de forma direta com o homem integral, que tem a oportunidade de se expor, de demonstrar suas habilidades e suas capacidades sem que haja a necessidade de determinar, medir ou julgar estereótipos e eleger funções para cada aluno. Ao contrário disso, nas aulas de Educação Física o aluno pode deixar fluir sua expressividade, pois é por meio dela que teremos a oportunidade de observar, despertar talentos futuros e incentivá-los para uma vida ativamente saudável através da prática de atividades físicas.

Pensamos ser esse o nosso papel de professor, ou seja, educar através do movimento também para a diversidade. Entendendo e acreditando na ação de educar em um contexto mais abrangente, esta pesquisa tem como objetivo verificar a atuação do professor de Educação Física diante da questão da homoafetividade em suas aulas e ainda detectar possíveis preconceitos e discriminação com os alunos homoafetivos masculino e feminino no âmbito da Educação Física escolar.

A fim de explicitar conceitos e justificar o termo homoafetividade 
adotado nesta pesquisa faremos algumas considerações sobre ele. Dias (2006) através de sua sensibilidade e pensamento jurídico, viu a necessidade de o termo homossexualidade ser substituído por homoafetividade, pois acredita que o mesmo afasta o seu uso marcado pelo preconceito, e ainda desvia o foco evidenciado pelo sexo como vinculo que une os pares, transferindo para o afeto com esta nova terminologia.

Sabemos que existe uma grande complexidade e falta de explicações comprovadas a respeito da questão homoafetiva feminina ou masculina, porém todas as áreas sejam elas biológicas, psicológicas, sociais e até mesmo religiosas, tentam buscar uma forma de explicar o que acontece com as pessoas homoafetivas, cada uma dentro de suas concepções.

Não se sabe ao certo se a homoafetividade é algo nato ou adquirido, apenas podemos dizer que é um grande enigma. A ciência biológica tenta explicar através de testes com indivíduos homoafetivos. Nos EUA, a neurocientista Simon Le Vay (1985) defende que a homoafetividade é definida geneticamente, não recebendo apenas influências ambientais. Em pesquisa realizada com homoafetivos a autora chegou à conclusão que o hipotálamo (região cerebral que controla certos impulsos sexuais) dos homoafetivos tem a metade do tamanho do hipotálamo dos heterossexuais e isto que está próximo ao tamanho hipotalâmico feminino.

Por outro lado a psicologia, de acordo com Dias (2006) considera que se trata de uma variação do desenvolvimento sexual, ou seja, ocorrido ainda na infância (até por volta dos 3 ou 4 anos de idade), sendo determinadas psiquicamente com origem na relação parental, onde é constituído o núcleo da identidade e personalidade, ou seja, firma-se no entendimento interior de ser masculino e feminino determinantes da orientação sexual.

Entendida sob a ótica da religiosidade a homoafetividade que, de acordo com Dias (2006) é a maior geradora de preconceitos ao considerar a homoafetividade como pecado da carne e ter como ideal a família composta por homem e mulher baseada no ideal de Adão e Eva.

Este conflito devido a tantas opiniões pode levar ao isolamento e preconceito relatados por Rodrigues et. al.(2007) ao relatar que isto ocorre devido à vida em sociedade ser definida pela orientação heterossexual, o que os leva a bares e espaços rotulados de gays.

Percebemos pelos depoimentos de alguns homoafetivos que afirmaram que foram criados para serem heteroafetivos e quando se depararam com uma orientação sexual diferente, começaram a aparecer os 
conflitos. Em um primeiro momento tentaram esconder esta realidade, como solução, pois o medo do preconceito, da rejeição da família e do meio social é notável. O dia-adia destas pessoas tornou-se muito difícil e a partir desta dificuldade que acabam buscando pessoas com a mesma orientação sexual e lugares onde freqüentam esse público com os mesmos pensamentos.

Pensando nisso consideramos a educação de uma criança como uma base que deve ser bem construída para que no futuro quando adulto seja capaz de conviver e entender as diferenças que nesse mundo não são poucas e estão presentes com maior intensidade e mais evidente nas escolas.

Para entendermos a trajetória da homoafetividade, suas conquistas e retrocessos, apresentamos algumas observações a respeito da evolução histórica deste processo para chegarmos aos dias atuais.

De acordo com Dourado (1963) as relações homoafetivas sempre existiram e desde a antiguidade clássica era praticado pelos adolescentes dóricos, Aristóteles justificava estas relações como medidas para evitar a superpopulação grega. Pode se deferir que na antiguidade os meninos deveriam ter algum contato sexual com outro homem, sendo que os escravos não podiam ter este contato e se tivessem eram punidos severamente. Estas atitudes refletem nos dias de hoje de forma velada, mas nos esclarecem algumas evoluções.

No que se refere a homoafetividade feminina, que, tem como sinônimo o termo lésbica na linguagem comum da sociedade e é citado por Oliveira (2006): deve-se a uma poetisa chamada Safo que vivia na ilha de Lesbos e relatava em seus poemas o amor homossexual feminino daí a designação lésbica para definir mulheres homoafetivas.

Aproximando da realidade contemporânea, encontramos em alguns países noticiados em jornais, revistas e, até em constituições os direitos dos homoafetivos tendo como exemplo a união estável e a adoção de crianças para casais homoafetivos, sejam masculinos ou femininos.

Estes exemplos mostram um pouco da trajetória e algumas conquistas já alcançadas pelo público aqui estudado. Mesmo assim podemos dizer que a evolução social da homoafetividade ainda é permeada pelo preconceito mostrando que vem de muito tempo e que está inserida no processo histórico.

\section{Educação física e gênero: pre- conceito e discriminação}

O professor de Educação Física pode contribuir no estabelecimento do preconceito e da discriminação 
se reforçar os estereótipos existentes através de seu discurso ou através de sua prática pedagógica. Existem professores que, embora não apresentem explicitamente tais comportamentos, também não apresentam nenhuma atitude efetiva no sentido de impedir as discriminações por parte dos outros alunos. Logo, acabam colaborando com a discriminação daqueles que não tem um comportamento ou perfil igual ao que a sociedade estabeleceu.

Cunha \& Melo (1996) explicitam que questões como preconceito e discriminação devem constituir-se em um grande desafio para os professores de Educação Física e que os indivíduos homoafetivos devem ser tratados com atenção, pois, ainda que as questões de gênero e classes mistas tenham sido tratadas, ainda são observáveis as situações preconceituosas e discriminatórias.

Corroborando com o autor, cremos que a Educação Física é para todos e os professores deveriam saber lidar com diferenças existentes entre os alunos, respeitando sua individualidade, afinal a Educação Física como meio educacional é uma das ferramentas que hoje faz grande diferença na escola, pois durante suas aulas o contato entre professor e aluno é mais próximo e isto facilita a interação.
Ainda ressaltamos a importância do professor de Educação Física em preparar-se para a convivência com as diferentes situações, como a homoafetividade, pois é uma situação que está presente na sociedade de todas as formas, e já pode ser observada em alunos no início de sua vida escolar. Portanto, também presente nas aulas de Educação Física onde os temas preconceitos e discriminação fazem parte do currículo escolar e permeiam as disciplinas nele inseridas. Para tanto, o professor deve ficar atento a todas as formas de comportamentos e atitudes dos alunos, tanto no emprego de determinadas palavras como em gestos e atitudes.

Apesar de professores terem maior afinidade com alguns alunos, sempre deverão atentar para o fato de que a turma é formada por vários deles, cada um com suas características físicas, biológicas, sociais e culturais, e que dependendo da relação estabelecida e da prática pedagógica desenvolvida, a adesão à prática de atividades físicas poderá ser favorável ou não. Lembrando que um dos papéis do professor de Educação Física é conscientizar e mostrar a importância da prática da atividade física regular para ter uma vida saudável e ainda mostrar que todos devem participar e "todos" é de forma indistinta. 
Quando nos referimos a gênero recorremos a Connel (1995, apud Altmann 1998) ao afirmar que, independente de classe, gênero, raça e outras diferenças, não devem existir uma separação ou exclusão e afirma que juntos é que se constroem as relações sociais e assim os indivíduos podem conviver e entender as diferenças de cada um, de forma harmoniosa e muito mais feliz, pois ainda hoje nas escolas existe uma presença de preconceitos e discriminações com os alunos que apresentam formas de comportamento e atitudes fora do padrão imposto pela sociedade, seja no sentido sexual, gênero, social, físico entre outros, por isso acreditamos na importância da escola, professores e alunos enquanto agentes desencadeadores de um processo de conscientização da existência e como trabalhar com elas.

Um professor deve buscar estudos alternativos que tornem sua aula cada vez mais participativa por todos, ou seja, suas aulas devem ser elaboradas de forma que apresente sentidos educativos como, por exemplo: usar de temas polêmicos como a homoafetividade, pois é uma situação existente em nosso cotidiano e em nossa sociedade sendo percebido na escola de forma significante, e o professor deve intervir com seus conhecimentos, confirmamos esse pensamento com a fala de ROSA (2004) que sugere que, a fim de que as relações preconceituosas sejam minimizadas, faz-se necessário que a formação do professor seja repensada a partir de valores não heterossexistas.

Acreditamos que para que isto ocorra o professor precisa ter uma base e um conhecimento significativo de assuntos variados, e é em sua graduação onde este conceito é formado. Assim, quando este professor precisar aliar teoria e prática através de suas aulas, não divida seus alunos e sim busque e mostre a eles, que todos podem fazer juntos e que não existem atividades exclusivamente masculinas ou femininas. Infelizmente, ainda podemos observar a divisão de meninos e meninas nas aulas de Educação Física durante as atividades, divisão esta que muitas vezes acontece devido a atitudes do professor.

Pensamos que esta atitude pode interferir na formação do aluno que pode assimilar e trazer esta separação para sua vida futura. A relação com a atividade ou esporte que o indivíduo pratica não deve ser comparada a sua orientação sexual, pois a prática de uma atividade corporal é apenas devido a identificação com a mesma. 
Homoafetividade $x$ atuação do professor de educação física

Consideramos que a atuação de todo professor é de extrema importância na formação de uma criança e que faz toda diferença quando o professor se preocupa e passa conhecimentos diversificados, esclarece assuntos que para eles geram dúvidas e algumas vezes são interpretados de maneira equivocada. O conjunto formado pela família, escola e sociedade onde relações são estabelecidas, é de grande importância na formação física, intelectual e social do individuo.

Como, neste trabalho, abordamos uma questão delicada e que envolve professores de educação física, não poderíamos deixar de dar ênfase a sua atuação enquanto prática pedagógica/ didática, ou seja, de como suas aulas são planejadas, ministradas e continuadas. Em aulas de Educação Física são inúmeras as questões e assuntos que podem ser levantados e discutidos através do esporte, atividade física e do lazer.

Pensamos que educar através de aulas co-educativas seria de muita importância e de grande aproveitamento para os alunos, mas colocar essas aulas em prática, pode se tornar um desafio a muitos professores de Educação Física, pois apesar de alguns saírem da graduação achando que estão prontos para o mercado, ainda não podem dizer que colocarão em prática os conhecimentos acumulados ao longo da graduação.

Segundo o Conselho Federal de Educação Física (CONFEF 2002):

O profissional de Educação Física é especialista em atividades físicas, nas suas diversas manifestações, tendo como propósito prestar serviços que favoreçam o desenvolvimento da educação e da saúde, contribuindo para a capacitação e/ou restabelecimento fisicorporal, visando à consecução do bemestar e da qualidade de vida, da consciência, auxiliando em toda parte física e estética e ainda contribuindo para a autonomia, cooperação, auto-estima, da solidariedade, da integração, da cidadania em fim das relações sociais e preservação do meio ambiente, devendo exercer tudo isso com muita ética, segurança e de forma individual e coletiva, e ainda respeitar as diversas manifestações e objetivos, de modo a atender as diferentes expressões do movimento humano presentes na sociedade, considerando o contexto social e histórico-cultural. 
Estas considerações são muito importantes quanto à atuação do profissional, afinal o mesmo deve ter total preocupação e preparação, pois podemos observar a grande responsabilidade que cabe ao profissional de Educação Física realizar, por isso acreditamos que sua formação, entendimento e até mesmo sua conscientização a respeito de diversos assuntos é de extrema importância para o processo educacional através de suas aulas.

\section{Metodologia}

Este estudo é caracterizado como pesquisa de campo de caráter qualitativo que teve como participantes cinco sujeitos homoafetivos (18 a 26 anos), 05 sujeitos heteroafetivos e 05 professores de Educação Física de ambos os sexos, que foram submetidos a uma entrevista semi-estruturada. Para a entrevista foi utilizado um gravador.

No que tange a entrevista semi-estruturada, Triviños (1987) a define como aquela que, embora se utilize um roteiro básico de questões, abre ao(s) informante(s) a possibilidade de segundo sua linha de pensamento e experiências, contribuir com novas visões/ questionamentos. É nesse sentido que os participantes se transformam em co-participantes no processo de investigação.
A entrevista foi conduzida perguntas formuladas sobre três pontos fundamentais: participação nas aulas de Educação Física, atitudes preconceituosas e postura profissional. Terminada a fase de coleta de dados as entrevistas foram transcritas para posterior análise mediante o procedimento da Análise de Discurso.

A Análise de Discurso visa compreender como os objetos simbólicos produzem sentidos saindo da esfera exclusiva da interpretação. Ela não procura um sentido de forma 'direta' ou 'objetiva', ou seja, não existe um esquema fechado de interpretação. O que existe é um dispositivo teórico que será utilizado pelo analista no momento em que este se dispor a compreender os sentidos desencadeados de acordo com a questão por ele formulada (ORLANDI, 2001).

A pergunta em Análise de Discurso não é 'o que é isso' mas sim 'qual o processo de produção do 'isso', o que leva o sujeito a falar de outro lugar social.

Para análise dos dados, após a transcrição das entrevistas, procuramos nas falas as marcas lingüísticas mais recorrentes nas entrevistas que conforme Orlandi (1992) revelam sentidos que foram ditos ou não ditos que estão subentendidos ou explícitos. 


\section{Dialogando com os resultados}

As marcas lingüísticas mais encontradas nas entrevistas dos Homoafetivos, Heteroafetivos e Professores de Educação Física foram:

\section{O sentido atribuído a homoa- fetividade}

a) Pelos homoafetivos: " por ser diferente "; " sentir algo diferente "; ." ser gay; sentia diferente "; lésbica, gay ".

b) Pelos heteroafetivos: " mais afeminados ou mais tímidos "; engraçado todo espalhafatoso "; ." jeitão meio esquisito tipo diferente "; " masculinizada e gay "; ". sapatão e gay ".

c) Pelos professores: " relação de duas pessoas do mesmo sexo; seja ela de forma sexual ou afetiva "; ." afeminados ou aquelas alunas que tem atitudes masculinas diferentes dos outros entende " ; " deve se que envolve afeto com pessoas iguais, do mesmo sexo diferente dos heterossexuais ser gay "; " tipo gostar do mesmo sexo, a própria nomenclatura, já diz é o afeto entre pessoas do mesmo sexo, muito interessante essa nova nomenclatura eu acho fica até mais bonito de se falar, é soa melhor ";

Pelas falas separadas de cada grupo percebemos a diferença conceitual entre eles no que se refere ao entendimento do termo Homoafetivo e que esta diferença relaciona-se com seu contexto social, pois como podemos perceber o primeiro grupo (homoafetivos) utiliza-se de palavras ligadas às experiências e sensações vivenciadas que não se vinculam aos aspectos biológicos e físicos, mas a sentimentos que em determinada época o fizeram vivenciar com outra pessoa do mesmo sexo, buscando uma forma de se entender. Quanto à palavra lésbica, gay podemos dizer que é o termo utilizado hoje no vocabulário popular.

Quanto aos Heteroafetivos as palavras utilizadas referem-se aos aspectos físicos, comportamentos e trejeitos, que em algumas vezes foram mencionados nas falas acompanhados de risos.

De acordo com Saraiva (1999, p.33) "Os estereótipos influenciam na percepção que os indivíduos têm de si próprios e dos outros e, portanto, influenciam nas relações interpessoais". Diante da colocação da autora podemos dizer que as falas reforçam o estereótipo de homoafetivos criados pela sociedade e expresso pela população, que um dia passou ou passará pela escola e pelas aulas de Educação Física e como conseqüência reproduzirá o contexto social.

O entendimento por parte dos professores de Educação Física 
sobre a Homoafetividade pode ser analisado sob diferentes aspectos: comportamental, biológico, social, ligados a sentimentos e nomenclatura. Quando feita esta pergunta aos professores alguns atentos ao prefixo HOMO já respondiam de imediato que se tratava de igualdade, mas no decorrer da entrevista se posicionavam melhor quanto ao entendimento do significado da palavra.

Verificamos a presença da palavra sexo acompanhada da palavra afeto em três falas de professores o que pode representar uma mudança de paradigma o que é muito importante no contexto educacional onde a presença da diversidade é um assunto, inclusive indicado pelos documentos do MEC a serem trabalhados, pela Educação Física dentro deste contexto. Nas aulas de Educação Física a diversidade deve ser respeitada e utilizada como ferramenta, conforme os $\mathrm{PCN}$ de $5^{\circ}$ a $8^{\circ}$ séries (1998, p.19):

O princípio da diversidade aplicase na construção dos processos de ensino e aprendizagem e orienta a escolha de objetivos e conteúdos, visando a ampliar as relações entre os conhecimentos da cultura corporal de movimento e os sujeitos da aprendizagem. Buscase legitimar as diversas possibilidades de aprendizagem que se estabelecem com a consideração das dimensões afetivas, cognitivas, motoras e socioculturais dos alunos.

Romper com este paradigma conforme Dias (2006) não significa apenas minimizar o preconceito, mas, principalmente evidenciar a origem do vínculo que une o par, independente do sexo que for, é o afeto.

\section{A presença dos homoafetivos nas aulas de Educação Física sob a ótica dos professores e alunos.}

a) Pelos homoafetivos: " segura essa bola igual homem e joga essa bola com força; "..." Professor realizou tipo brincadeiras de competição, aí dividia meninos e meninas "..." vem com a gente ela parece homem mesmo "; " teria um campeonato de vôlei, futebol e tinha apresentação de dança, eu então quis participar, então chegou o dia da apresentação e eu era o único menino no meio "; " futebol e coisa de moleque vai jogar vôlei, os meninos não vão ficar a vontade com você aqui "; " não era muito apto, não jogava bem, fiquei de goleiro ".

b) Pelos heteroafetivos: " Trazer para escola sem dúvida, seja na educação física ou em qualquer aula, daí quem sabe fica mais fácil das pessoas entenderem " ; ' na escola que aprendemos tudo, 
e também em casa com nossa família, na rua, no trabalho e com amigos... Não só esse, mas como os tantos outros tipo drogas, sexo, gravidez ";

"Era preconceituoso mesmo sabe ainda é difícil entender mais o mundo ta tão moderna, mas eu não sou a favor e se tivesse um filho viado (risos) acho que não saberia lidar e nem aceitar seria difícil cara ";

" Hum isso é um assunto delicado acredito eu, que deve ser visto com muita cautela, pois afirmar o que uma pessoa é, é bastante complicado ";

" Eu não sei de dizer se esta correta, mas sei que tem muito, hem tanto mulher quanto homem, até que duas mulheres se forem gostosa até vai (risos). Agora dois machos não dá né? é esquisito ".

c) Pelos professores: " assunto muito complexo e instigante "; " é um pouco complicado "; " é difícil... Foge um pouquinho de minha criação "; " terem suas oportunidades "; " bastante delicado, mas legal não e tão fácil ".

Percebemos que a presença dos Homoafetivos nas aulas de Educação Física é um assunto que poderíamos discutir muito neste trabalho e sob vários aspectos. No entanto nos restringiremos às falas que certamente demonstrará a sua complexidade e a existência de uma Educação Física ainda calcada em conteúdos esportivos e técnicos relacionados à força e resistência.

Em uma das falas observamos que em aulas de Educação Física ainda utiliza-se a separação por equipes meninos e meninas. Sabemos que quando eles interagem, valores são estabelecidos, principalmente na questão de gênero. Nestes momentos a menina e o menino têm oportunidade de se conhecerem e dentro deste conhecimento se respeitar.

Os heteroafetivos, no que se referem ao assunto da escola consideram discutir a presença dos homoafetivos, mas também de outros assuntos como drogas, gravidez, sexo. Embora considerem importantes pensam que devem ser discutidos estes temas com cautela e cuidado, o que nos faz pensar na falta de naturalidade como são relatados e ao mesmo tempo reconhecidos como existentes hoje em número significativo.

Nas entrevistas observamos atitudes bastante interessantes de como as pessoas enxergam e reconhecem a existência dos fatos na sociedade, e dentro dela tudo pode ocorrer porém em uma esfera menor, como por exemplo, num contexto familiar a mesma situação se configura de forma diferente como é o caso desta entrevista:

"Era preconceituoso mesmo sabe ainda é difícil entender mais o mundo ta tão moderna, mas 
eu não sou a favor e se tivesse um filho viado (risos) acho que não saberia lidar e nem aceitar seria difícil cara;

As palavras que predominaram nesta pergunta feita aos professores denotam complexidade, dificuldade e delicadeza ao assunto quando devem discutir a presença de homoafetivos em suas aulas.

Diante destes termos recorremos a Rosa (2004, p.88) quando diz que:

É justamente nesse momento que o professor tem de pensar alguma estratégia de atuação no sentido de "desmistificar" esse preconceito. Por isso, resgato nesse encontro a concepção de aulas co-educativas na educação e na educação física.

\section{3. $A$ relação da homoafetividade com atitudes preconceituosas e discriminatórias.}

a) Pelos homoafetivos: " piadinhas " "vista grossa "; " parece homem ". "piadinhas brincadeiras de mal gosto."; " comentários maldosos ". ," isso não é coisa de homem "., . viadinho " "bichinha"; " Maria João "; " mulherzinha, fracote, comentários bobos ";

a) Pelos heteroafetivos: " bichinha, viadinho "' " comentários bobos "; " viado, bicha, da ré no quibe, fresco, zuar "; "é só falação, é um querendo tirar do outro ", não perdoam nada; " é esquisito ".

\section{c) Pelos professores:}

" Se falasse que estou preparada estaria mentindo; " curioso não tinha parado para refletir "; " não depende só de nós professores a educação e a compreensão dos alunos "; " eu não posso te dizer que estou preparada sempre, sobre essa questão ai entendendo só o que vejo no dia a dia, na televisão e ate mesmo com nossos alunos, pois sei que e difícil para eles pois eles sabem que são diferentes, certo? ";

Os grupos que representam os homoafetivos e heteroafetivos utilizam-se das mesmas palavras que tem o mesmo sentido, porém não o mesmo significado. São palavras do senso comum com teor pejorativo. Pensamos que existe um preconceito explícito e uma discriminação declarada. O que já não ocorre por parte dos professores, os quais revelam um preconceito velado e uma discriminação camuflada atribuindo e delegando seu papel à sociedade e a família como se sua responsabilidade enquanto educador desta forma pudesse ser diluído.

Ficou evidente na fala dos professores que ter conhecimento da existência do preconceito e de qualquer processo discriminatório não significa aceitar ou mesmo entender a 
situação. A aceitação passa por ruptura de sentimentos e esbarra em processo de formação que nem sempre são fáceis de serem trabalhados. Pensamos que se estas questões internas não são entendidas fica difícil passar externamente, mesmo como educador, ações diferentes das sentidas, e é o que percebemos com o temo adaptar, que nos passa uma modelagem ou uma reforma em cima de algo já construído.

É importante registrar a palavra "preparada" presente nas falas e que nos leva a questionar o que eles entendem por "não me sinto preparada "? Em cima dessa pergunta elaboramos outras: Quando nos sentimos? O que nos faz sentir preparado ou não? Será que estas oportunidades que a escola enquanto espaço social, onde o acesso é para todos, portanto tudo pode acontecer, não seria o momento melhor para nos prepararmos?

Ficam aqui estas questões para nós refletirmos. Nós acadêmicos, professores, participantes deste estudo e todos que pensam em desenvolver trabalhos com a intenção de não respondê-las, mas de usá-las como trampolim para outras pesquisas.

\section{Considerações finais}

Antes de fazermos as considerações finais gostaríamos de regis- trar uma fala que, por corresponder a uma professora de Educação Física, não poderíamos deixar de mencionála, pois reconhecemos o nosso papel de educador como agente transformador e incansável e que diante de um "muito obrigado pela participação e parabenização pelo assunto e pela coragem" nos torna mais corajosos e capazes no trabalho e na crença das mudanças pela educação.

Deste estudo observamos que a atuação dos professores de Educação Física com as questões da homoafetividade ainda não está presente em suas aulas a não ser quando surge uma situação de conflito entre os alunos, mas não é tratado como conteúdo ou presente neles. Este assunto aparece nas aulas de Educação Física por situações provocadas pelo corpo discente.

Mesmo presente nestas condições os professores se sentem "pisando em ovos" para tratá-lo. A discriminação e o preconceito explícito são percebidos pelos alunos homoafetivos e pela população heteroafetiva, mas também está presente na fala dos professores de uma maneira discreta e velada.

No final deste estudo pensamos que é grande a necessidade de se discutir na formação acadêmica dos profissionais de Educação Física, as diferenças que compõe a sociedade brasileira, principalmente a homoafetividade, com o objetivo de 
desconstruir preconceitos sociais, pois somente contemplando nossos alunos na sua plenitude de ser humano que podemos incidir em uma prática pedagógica realmente democrática.

\section{Referências}

\section{ALTMANN, Helena. Rompendo} fronteiras de gênero: Marias [e] Homens na Educação física. Belo Horizonte, Faculdade de Educação da UFMG, (Monografia de graduação em Educação), 1998.p.8.

BRASIL. Ministério de Educação e Cultura. Secretaria de Educação Fundamental. Parâmetros Curriculares Nacionais: Terceiro e quartos ciclos do ensino fundamental. Brasília: MEC/ SEF, 1998. p.19.

BRASIL. Constituição da República Federativa do Brasil, São Paulo. Saraiva, 2003.p.131.

CONFEF (Conselho Federal De Educação Física), 2002.

DIAS, Maria Berenice. União Homossexual. Porto Alegre: Livraria do advogado, 2006.p.1827-34-38-40-96-97.

DOURADO, Luiz Ângelo. Homossexualismo e Delinqüência. Rio de janeiro: Zahar. 1963.p.17.

CUNHA JUNIOR, Carlos Fernando Ferreira; MELO, Victor Andrade.
Homossexualidade, Educação Física e Esporte. Rio de janeiro: movimento ano III,1996. p.23.. OLIVEIRA, Marcos Aurélio Taborda.

Educação Física escolar e ditadura militar no Brasil (1968-1984): h i s tór i a e h i s tori o grafia. Educação e Pesquisa, São Paulo, v.28, n.1, p. 51-75, jan./jun. 2002 OLIVEIRA, Mariney Maciel. Homossexualidade feminina e suas implicações sociais no âmbito familiar. Campo Grande, Curso de Serviço Social UCDB, (monografia de graduação em serviço social). 2006 . p.13-14. ORLANDI, Eni Pucinelli. Análise de Discurso: princípios e fundamentos. 3.ed.,

Campinas, SP: Pontes, 2001.

RODRIGUES, Gisele et. al. A família do novo milênio - homoafetivos e suas relações interfamiliares. Campo Grande, curso de Comunicação Social UCDB, (Dissertação em graduação em jornalismo). 2007 p.14.

ROSA, Marcelo Victor: Educação

Física e Homossexualidade: Investigando as representações sociais dos estímulos do controle de desporto/UFSC, 2004.p.84115.

SARAIVA, Maria do Carmo. Coeducação física e esportes. Ijuí: ed. unijuí 1999. p. 191.

Recebido: 30/agosto/2009 Aprovado: 20/outubro/2009 